\title{
Classical conditioning of heart-rate deceleration in the rat with continuous and partial reinforcement
}

ROBERT D. FITZGERALD AND RICHARD M. VARDARIS, UNIVERSITY OF OREGON MEDICAL SCHOOL JUDSON S. BROWN, UNIVERSITY OF IOWA

Classical conditioning of heart rate was studied in three groups of rats receiving either $100 \%, 50 \%$, or $0 \%$ reinforcement. All groups were given two days of acquisition and one day of extinction. A deceleration in heart rate was observed as the $\mathrm{CR}$ for the $100 \%$ and $50 \%$ groups. The magnitudes of the CRs failed to diminish over 24 extinction trials.

In a previous investigation of classically conditioned heart rate (HR) in the dog, greater resistance to extinction was observed following partial reinforcement as compared to continuous reinforcement (Fitzgerald et al, in press). One purpose of the present study was to determine if this partial reinforcement effect (PRE) would also obtain in the rat. A second purpose was to provide data on the question of the direction of the conditioned HR change in the rat as both accelerations and decelerations have been reported (cf., Holdstock \& Schwartzbaum, 1965; McDonald, Stern, \& Hahn, 1963). Method

Subjects and apparatus. The Ss were 36 Hooded LongEvans rats weighing approximately $350 \mathrm{gm}$. The Ss were restrained in a plastic dome rat holder manufactured by $\mathrm{E} \& \mathrm{M}$ Instrument Company. Hypodermic needles positioned under the skin along either side of the rib cage served as EKG recording electrodes. The CS was a 7-sec., $1000 \mathrm{cps}$ tone, and the US, a 1-sec., 1.8-ma, 60-cycle, ac shock delivered through the EKG electrodes. The CS-US interval was $6 \mathrm{sec}$. with the US overlapping the final 1 sec. of the CS.

Procedure. There were three groups of $12 \mathrm{Ss}$ each receiving training on two successive days. The first day consisted of 28 acquisition trials preceded by 30 pre-test trials with CS alone at 1-min. intervals. On the second day an additional 14 acquisition trials followed by 24 extinction trials were given. A period of from 10 to $15 \mathrm{~min}$. elapsed between the time that $S$ was placed in the restraining device and the presentation of the first acquisition trial on the second day. For one experimental group (E-100\%), all acquisition trials on each day were reinforced, while for a second experimental group $(\mathrm{E}-50 \%)$, half the trials were reinforced (R) and half were nonreinforced (NR) according to a random schedule. The third group (C) served as a pseudo-conditioning control and was treated like the E-50\% group except that the US and CS were never paired. On half of the trials for this group the US preceded the CS by $5 \mathrm{~min}$., and on the other half of the trials, only the CS was presented. The mean intertrial interval for all groups during both acquisition and extinction was $10 \mathrm{~min}$.

\section{Results}

The UR, measured in the first 6 sec. after shock, was invariably an acceleration in HR. The CR was measured on each trial as the beats-per-minute (bpm) rate in the 6-sec. CS-US interval minus the bpm rate in the $6 \mathrm{sec}$. immediately preceding the onset of the CS. Figure 1 shows these difference scores averaged over two trial blocks of the first day of acquisition. This figure reveals that the HR reactions to the CS of all three groups were decelerative. However, the magnitude of these reactions increased over trials for the $\mathrm{E}$ groups but not for the $\mathrm{C}$ group. An analysis of variance showed that the overall differences between groups was reliable $(F=4.98, p<.025)$ as was the groups by trials interaction $(F=2.84, p<.001)$. There were no significant differences between the E-100\% and E-50\% groups. The results obtained on the second day of the experiment are plotted in Fig. 2. It is evident from this figure that the CRs of the $\mathrm{E}$ groups during acquisition continued to be greater than the responses shown by the $\mathrm{C}$ group $(\mathrm{F}=3.35, \mathrm{p}<.05)$. The $\mathrm{E}$ groups also showed an unexpected loss in CR magnitude between the first and second two-trial blocks of acquisition $(t=3.64$, $\mathrm{p}<.01$ ). While not shown, mean pre-CS HR of the E-100\%, E-50\%, and C groups decreased during this period by $37.9(t=12.64, p<.001), 35.4(t=3.29, p<.01)$, and $39.8(t=4.88, p<.001) b p m$, respectively. It should be clear, therefore, that the diminished CRs of the $100 \%$

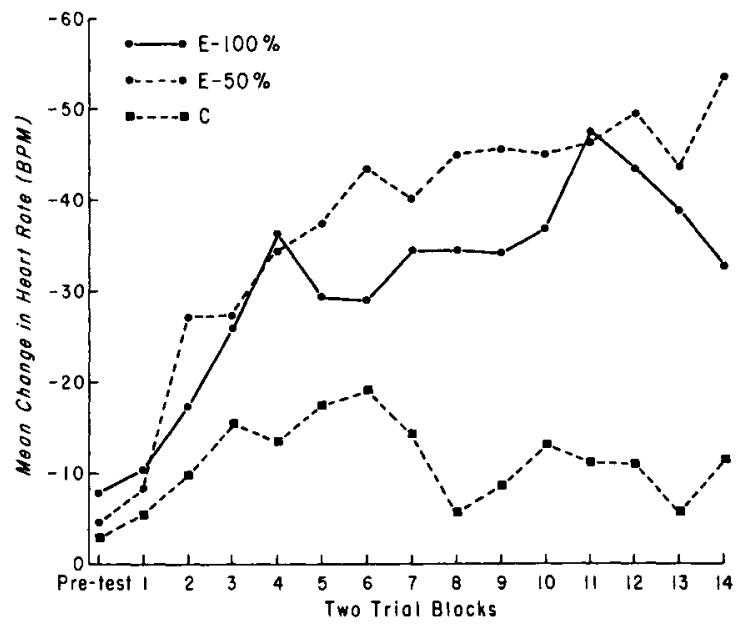

Fig. 1. HR decreases to the $C S$ during the first day of acquisition. The first points on the far left refer to the HR responses on the last five pre-test trials. 


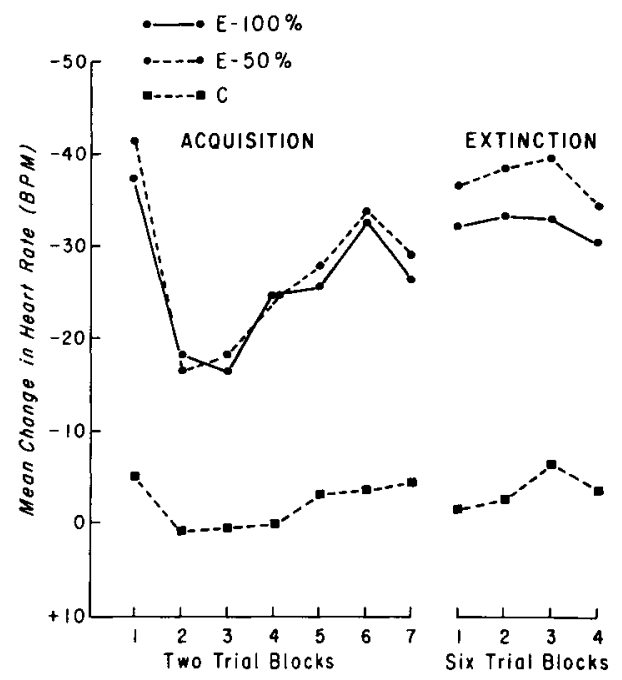

Fig. 2. HR changes to the $\mathrm{CS}$ during the second day of acquisition and during extinction.

and $\mathbf{5 0 \%}$ groups can be accounted for by the decreases in their pre-CS heart rate. On subsequent trials the pre-CS scores for all the groups increased to their original levels. At no other time in the experiment were there reliable changes in pre-CS HR over trials, nor were there any significant overall differences between groups in this measure. The pre-CS bpm levels averaged over acquisition and extinction were: $100 \%-$ $406,50 \%-399$, and $\mathrm{C}-410$. The results on the right of Fig. 2 are plotted in six trial blocks to save space, as neither $E$ group revealed evidence of a response decrement in extinction. The only significant effect in extinction was that of the overall difference among the three groups $(F=10.06, p<.001)$.

In order to show the form of the HR reactions during the CS, the CS-US interval was divided into three successive 2-sec. periods and bpm rates, corrected for pre-CS level, determined for each period. On NR trials, corrected bpm rates were also found for the interval when shock would have occurred and for three successive 2-sec. periods following the termination of the CS. These results, when averaged over successive seven-trial blocks on each day of acquisition, provided no evidence for an accelerative $C R$ in any measurement period. In addition, the forms of the responses of the $\mathrm{E}$ and $\mathrm{C}$ groups were markedly different. The magnitude of HR deceleration increased for both $\mathrm{E}$ groups during the $\mathrm{CS}$, while for the $\mathrm{C}$ group it decreased. This analysis also disclosed that the rather substantial decelerative reactions of the $\mathrm{C}$ group shown in Fig. 1 occurred mainly in the first $4 \mathrm{sec}$. of the CS. An analysis of variance of the three CS-US periods provided a significant periods effect $(F=9.68, p<.001)$, a significant groups effect $(F=5.44, p<.01)$, and a significant groups by periods interaction $(F=8.20$, $\mathrm{p}<.001)$.

\section{Discussion}

The extinction results of this investigation cannot be applied to the problem of whether the PRE obtains for conditioned $\mathrm{HR}$ in the rat as the number of extinction trials was insufficient to produce a decrement in the performance of either $\mathrm{E}$ group.

In agreement with results obtained by Holdstock \& Schwartzbaum (1965) using a similar conditioning procedure, the direction of the conditioned HR response in the current study was decelerative. Other investigators (Fehr \& Stern, 1965; McDonald, Stern, \& Hahn, 1963) have reported an accelerative $C R$ in rats, although, as the authors pointed out, the CR was in fact decelerative on the early trials of acquisition becoming accelerative on later trials. The current experiment failed to provide uny evidence of such a reversal in the direction of the $C R$ even though the number of trials was presumably sufficient for it to occur. It is quite possible, however, that methodological differences between the studies may have produced these seemingly divergent results. For example, in their studies, the Ss were relatively free moving, while in the present experiment they were restrained. Conceivably, this restraint prevented skeletal responses from occurring which might have produced an acceleration in HR. It should also be mentioned at this point that the decelerations that we observed cannot be attributed to the cessation of struggling during the CS as struggling, in general, was very infrequent.

The CRs of the E groups, while still obviously decelerative, were diminished in magnitude after the first two trials on the second day of acquisition. These reductions were caused by substantial decreases in pre-CS HR rather than by increases in $\mathrm{HR}$ during the CS. Just why these base-line decreases occurred is not clear. The fact that the pre-CS level of the $C$ group fell in a similar manner means that paired CS-US presentations can apparently be ruled out as a necessary condition. The decreases were also independent of the absolute pre-CS levels of the groups as these levels at the start of the second day of acquisition were comparable to what they were throughout the first day of acquisition.

\section{References}

Fehr, Fred S., \& Stern, John A. Heart rate conditioning in the rat. J. psychosom. Res., 1965, 8, $441-453$.

Fitzgerald, R. D., Vardaris, R. M., \& Teyler, T. J. The effects of partial reinforcement followed by continuous reinforcement on classically conditioned heart rate in the dog. J. comp. physiol. Psychol., in press.

Holdstock, T. L., \& Schwartzbaum, J. S. Classical conditioning of heart rate and galvanic skin response in the rat. Psychophy siolo$g y, 1965,2,25-38$.

McDonald, D. G., Stern, J. A., \& Hahn, W. W. Classical heart rate conditioning in the rat. J. Psychosomat. Med., 1963, 7, 97-106.

\section{Note}

1. This research was supported by Grant $\mathrm{HE} 06$ 335-06 from the National Heart Institute, and by Grant GB-2221 from the National Science Foundation. 